\title{
Management of patients with acute hyperkalemia
}

\author{
Meghan J. Elliott MD, Paul E. Ronksley MSc, Catherine M. Clase MB MSc, \\ Sofia B. Ahmed MD MMSc, Brenda R. Hemmelgarn MD PhD
}

Previously published at www.cmaj.ca

\section{The case}

A 72-year-old man presents to his family physician for follow-up of hypertension, reporting fatigue and generalized weakness. His medical history also includes peptic ulcer disease, type 2 diabetes mellitus and chronic kidney disease. The estimated glomerular filtration rate is $30 \mathrm{~mL} / \mathrm{min}$ per $1.73 \mathrm{~m}^{2}$. His medications include metformin, lansoprazole, acetylsalicylic acid, hydrochlorothiazide and ramipril, the dose of which was increased two weeks earlier to address suboptimal blood pressure control. Blood work at the time of the current presentation shows that the serum potassium level is 6.7 (normal range 3.3-5.1) $\mathrm{mmol} / \mathrm{L}$ from a nonhemolyzed sample. The patient's family physician refers him to the emergency department urgently. In the emergency department, the patient is hemodynamically stable, with blood pressure $124 / 70 \mathrm{~mm} \mathrm{Hg}$ and heart rate 80 beats/min (regular). Repeat testing shows a potassium level of $6.9 \mathrm{mmol} / \mathrm{L}$, and electrocardiography shows sinus rhythm with peaked T waves, prolonged PR interval (240 milliseconds) and a narrow QRS interval. This patient requires urgent treatment of hyperkalemia. What therapeutic options are available, and what is the evidence supporting their use?

$\mathrm{H}$ yperkalemia is a common disorder, occurring both in the outpatient setting and in up to $10 \%$ of patients who have been admitted to hospital. ${ }^{1-4}$ Underlying renal insufficiency and use of medications that disrupt potassium balance, such as angiotensin-converting enzyme inhibitors and potassium-sparing diuretics, are welldescribed risk factors. ${ }^{4-7}$ Although mild hyperkalemia is often asymptomatic and easily treated, acute, severe hyperkalemia that is left untreated can result in fatal cardiac arrhythmias. ${ }^{8-10}$ In addition to discontinuation of precipitants, steps in the management of acute hyperkalemia include protecting the heart from arrhythmias by administering calcium-based salts, ${ }^{11}$ shifting potassium into the cells and enhancing elimination of potassium. Several treatment options have been proposed, particularly for shifting potassium into the cells, with differing onset and duration of action. ${ }^{12}$ In addition, available studies conflict with respect to the efficacy of the various treatment options, which has led to differences in recommendations among practitioners and institutions. ${ }^{5,13}$

\section{Key points}

- Hyperkalemia is a common disorder that can be fatal if unrecognized or untreated.

- Insulin administered intravenously has the fastest onset of action and is very effective in reducing serum potassium.

- $\quad \beta_{2}$-Adrenergic agonists are as effective as insulin for lowering serum potassium and have a longer duration of action.

- The combination of $\beta_{2}$-agonists and insulin is more effective than either treatment alone.

- The use of intravenously administered sodium bicarbonate for the management of acute hyperkalemia is supported only by studies with weak and equivocal results.

The level of potassium at which treatment should be initiated has not been established by evidence. However, we recommend initiating nonpharmacologic steps for management at levels above $5.5 \mathrm{mmol} / \mathrm{L}$, with pharmacologic interventions as outlined in this review being instituted at levels of $6.0 \mathrm{mmol} / \mathrm{L}$ or greater.

Given uncertainties regarding the optimal management of this condition, we undertook a review of randomized controlled trials of therapies for the management of acute hyperkalemia in the adult population.

\section{Methods}

For the current review, we updated a previously published systematic review on this topic, ${ }^{14}$ using a similar search strategy and similar criteria for selecting studies for inclusion. We identified all potentially relevant articles, regardless of language of publication, by searching MEDLINE (2003 to February week 3, 2009) and EMBASE (2003 to week 9, 2009), according to a standardized protocol. We enhanced our searches by scanning the bibliographies of identified research and review articles and by reviewing the proceedings of all annual scientific meetings held between 2003 and 2009 of the American Society of Nephrology and the Canadian Society of Nephrology. All relevant studies published before 2003 were identified in the prior systematic review. ${ }^{14}$

From the Department of Medicine (Elliot, Ahmed, Hemmelgarn) and the Department of Community Health Sciences (Ronksley, Hemmelgarn), University of Calgary, Calgary, Alta.; and the Departments of Medicine and of Clinical Epidemiology and Biostatistics (Clase), McMaster University, Hamilton, Ont.

CMAJ 2010. DOI:10.1503/cmaj.100461 
We developed our search of the electronic databases with the assistance of a qualified librarian. We specified two comprehensive search themes: hyperkalemia and randomized trials. To identify relevant terms related to hyperkalemia (theme 1), the first search used the Boolean operator "or" to explode (i.e., search by all keywords more distal in the database thesaurus) and map (i.e., search by keyword) the MeSH heading "hyperkalemia" or the text words "hyperkal\$" or "hyperpotass\$" (where $\$$ indicates truncation). To identify relevant study methodology (theme 2), we performed a second Boolean search using the sensitive randomized controlled trial (RCT) filter outlined by Egger and colleagues. ${ }^{15} \mathrm{We}$ combined these two comprehensive themes using the Boolean operator "and."

Two reviewers (M.J.E. and B.R.H.) independently evaluated articles for eligibility in a two-stage procedure. In the first stage, the reviewers assessed all identified abstracts for possible eligibility. For abstracts selected by either individual, we retrieved the corresponding articles for full-text review. Eligible articles examined in this second stage were RCTs, quasiRCTs (i.e., trials with a quasi-random method for assigning participants to treatment groups, for example, by birth month or medical record number) and randomized crossover studies of adults with pharmacologic and nonpharmacologic interventions for acute hyperkalemia and an outcome of serum potassium concentration before and after the intervention. If data on serum potassium levels before and after treatment were incomplete or unavailable, we attempted to contact the investigators for additional information.

Each reviewer independently extracted data from the included studies using a predefined data abstraction form, resolving disagreements by consensus. The reviewers abstracted data on participants' demographic characteristics, presence of dialysis, definition of hyperkalemia, details of the treatment strategies and serum potassium values at baseline and at various times after treatment. We assessed several aspects of study quality, specifically study design, randomization process, allocation concealment, blinding, intention-totreat analysis and description of loss to follow-up. We assigned to each study a numeric score incorporating these elements of study quality according to a system described by Jadad and colleagues. ${ }^{16}$ The reporting in this systematic review followed the Preferred Reporting Items for Systematic Reviews and Meta-Analyses (PRISMA) statement. ${ }^{17}$ The primary outcome was change in serum potassium level with a given therapy. The secondary outcomes were adverse events associated with hyperkalemia, including electrocardiographic (ECG) changes, arrhythmia, death and adverse reactions to therapy for hyperkalemia.

\section{Results}

Through our updated search from 2003 to 2009, we identified 2158 potentially relevant articles. Of these, we retrieved the full text of nine articles for further review $(\kappa=0.94,95 \%$ confidence interval [CI] 0.83-1.00). We excluded three of these studies because treatment allocation had not been randomized. ${ }^{18-20}$ One study, published in 2003, was included in the prior review. ${ }^{21}$ Therefore, we included in this updated review 5 new studies, ${ }^{22-26}$ along with the 11 studies $^{21,27-36}$ reviewed by Mahoney and associates ${ }^{14}$ (Appendix 1, available at www.cmaj.ca/cgi/content/full/cmaj.100461/DC1).

The quality of the studies was variable, but in general it was poor. Only five studies (31\%) reported allocation concealment, only one reported that the analysis was performed on an intention-to-treat basis, and a small number had blinding of either patients or outcome assessors (Appendix 2, available at www.cmaj.ca/cgi/content/full/cmaj.100461/DC1).

\section{What treatment options are available?}

A variety of treatment options are considered for the acute management of hyperkalemia, including insulin, $\beta_{2}$-adrenergic agonists (inhaled, nebulized and intravenous), bicarbonate, resins, fludrocortisone, aminopylline and dialysis. In the sections below, we review the evidence for the use of each of these agents.

\section{Insulin}

In addition to four studies $(n=120)$ from the prior review, $28,30,31,34$ we identified one new RCT examining the effect of insulin in the management of hyperkalemia ${ }^{26}$ (Appendix 3, available at www.cmaj.ca/cgi/content/full/cmaj.100461/DC1). In that study, 16 patients with documented hyperkalemia at the onset of the anhepatic (no liver) stage of orthotopic liver transplantation (in which the new liver was transplanted into the original location) were randomly assigned to receive intraoperative infusion of insulin or no insulin.

Three of the five studies reported the immediate effects of insulin (at doses of 10 to 20 units $^{26,28}$ or $5 \mathrm{mU} / \mathrm{kg}$ per minute ${ }^{30}$ ) on serum potassium. Absolute reductions of $0.45 \mathrm{mmol} / \mathrm{L},{ }^{28}$ $0.55 \mathrm{mmol} / \mathrm{L}^{30}$ and $0.61 \mathrm{mmol} / \mathrm{L}^{26}$ were reported at the earliest time points, within 15 minutes. The other two studies reported reductions in serum potassium of $0.87 \mathrm{mmol} / \mathrm{L}$ at 30 minutes $^{31}$ and $0.47 \mathrm{mmol} / \mathrm{L}$ at 60 minutes. ${ }^{34}$ The reduction in potassium was sustained for up to two hours after administration, with a maximum reduction of 0.6 to $1.0 \mathrm{mmol} / \mathrm{L}$, after which gradual rebound was evident. Insulin treatment resulted in greater reductions in serum potassium at 30 minutes $(0.86 \mathrm{mmol} / \mathrm{L})$ than occurred with bicarbonate or albuterol; however, by two hours, the response was similar to that observed with albuterol $(0.90 \mathrm{mmol} / \mathrm{L}){ }^{31}$ Similar results were reported by Allon and Shanklin..$^{30}$

Three of the studies ${ }^{26,28,30}$ reported transient hyperglycemia within 15 minutes after treatment, with subsequent hypoglycemia (at 60 minutes) in one study. ${ }^{28}$ Of 40 patients with ECG changes characteristic of hyperkalemia at baseline, 21 $(52 \%)$ experienced normalization within one hour of treatment. ${ }^{31}$ These results were not presented by treatment arm, so we could not evaluate the influence of insulin alone on resolution of ECG changes. None of the authors reported any other clinically significant adverse effects.

\section{Inhaled, nebulized and intravenous $\boldsymbol{\beta}_{2}$-agonists}

In addition to seven studies in the prior review evaluating the effects of $\beta_{2}$-adrenergic agonists for the management of acute hyperkalemia, ${ }^{21,27-31,33}$ we identified one study comparing nebu- 
lized with intravenous salbutamol in 68 patients with chronic kidney disease $\mathrm{e}^{22}$ (Appendices 4 and 5, available at www.cmaj .ca/cgi/content/full/cmaj.100461/DC1). $\beta_{2}$-Agonist therapy, by inhalation, nebulization and/or intravenous administration, was studied in a total of 219 patients, most of whom were undergoing long-term hemodialysis.

In all studies, a response to $\beta_{2}$-agonists was seen at 30 minutes, irrespective of the formulation used. Standard doses ranged from 10 to $20 \mathrm{mg}$ for the inhaled forms $\mathrm{s}^{21,22,27-30,33}$ and from 0.5 to $2.5 \mathrm{mg}$ when administered intravenously. ${ }^{22,31} \mathrm{~A}$ decrease in serum potassium of 0.3 to $0.6 \mathrm{mmol} / \mathrm{L}$ was seen at this time point, with further reductions from baseline of up to 0.85 (after nebulized treatment) ${ }^{27}$ and up to $0.99 \mathrm{mmol} / \mathrm{L}$ (after intravenous treatment) ${ }^{31}$ at one hour. Reductions in serum potassium were more pronounced with higher doses of $\beta_{2}$-agonist; at 30 minutes, the decrease was 0.30 with 10 $\mathrm{mg}$ treatment and $0.60 \mathrm{mmol} / \mathrm{L}$ with $20-\mathrm{mg}$ treatment. ${ }^{27}$ This difference was preserved at 60 minutes, with decreases in serum potassium of 0.50 and $0.85 \mathrm{mmol} / \mathrm{L}$, respectively. Relative to placebo, these decreases were statistically significant at all time points; however, the difference in response between the two doses of albuterol was statistically significant only at 120 minutes.

Nebulized albuterol and levalbuterol were equally effective at lowering serum potassium, when compared with placebo; however, levalbuterol achieved a more immediate response upon administration and resulted in fewer adverse effects. ${ }^{21}$ In one study of salbutamol by metered-dose inhaler with a spacer device, a paradoxical rise of at least $0.1 \mathrm{mmol} / \mathrm{L}$ in serum potassium occurred in $59 \%$ of patients within one minute of treatment. ${ }^{33}$ No head-to-head studies have compared $\beta_{2}$-agonists delivered by metered-dose inhalers with a spacer device with other $\beta_{2}$-agonist formulations or other treatment classes; therefore, we cannot draw conclusions as to the relative efficacy of this mode of administration. In one study, intravenous salbutamol generated maximal reduction in serum potassium more quickly than nebulized salbutamol (one hour v. two hours); however, differences between groups were not statistically significant ${ }^{22}$ (Appendix 4).

The most commonly reported adverse effects were increased heart rate, ${ }^{21,27-29,33}$ tremors, ${ }^{21,22}$ palpitations ${ }^{21,22}$ and mild anxiety. ${ }^{27}$ Intravenous treatment may confer more adverse effects than nebulized treatment, including palpitations, increased blood pressure and migraine $; 2$ mild increases in blood glucose with both intravenous and nebulized administration were also reported..$^{28-31,33}$

\section{Sodium bicarbonate}

Two studies investigated infusion of sodium bicarbonate for the management of hyperkalemia ${ }^{30,31}$ (Appendix 5). One reported a small absolute reduction in serum potassium from baseline of 0.47 (standard deviation [SD] 0.31) $\mathrm{mmol} / \mathrm{L}(p=0.001)$ at 30 minutes ${ }^{31}$ in the other trial, there was no significant change in serum potassium at 30 and 60 minutes, relative to placebo..$^{30}$ The trials of bicarbonate infusion had the lowest reduction in mean serum potassium among all single and combined modalities, including salbutamol and insulin.

\section{Resins}

Only one small trial, involving patients undergoing hemodialysis, has evaluated the effects of sodium polystyrene sulfonate resins for the management of hyperkalemia. ${ }^{32}$ The authors reported no significant decrease in mean serum potassium at four hours relative to placebo and laxative (Appendix 5). There was a trend toward increasing serum potassium throughout the study, which was less pronounced in the resin arm. The study had several limitations, including normal serum potassium level at baseline and ingestion of a standardized meal containing about $20 \mathrm{mmol}$ of potassium at the fourhour time point, which made it difficult to interpret subsequent results.

\section{Fludrocortisone}

In a study of patients undergoing long-term hemodialysis who had predialysis hyperkalemia, fludrocortisone at a dose of 0.1 $\mathrm{mg} /$ day did not result in a significant decrease in serum potassium at three months, even after adjustment for number of hours of dialysis per week ${ }^{25}$ (Appendix 5). There were no reported adverse effects with this drug, although its use would be limited to long-term management of hyperkalemia.

\section{Aminophylline}

In a single trial comparing intravenous aminophylline with infusion of insulin and dextrose, aminophylline resulted in a decrease in serum potassium of 0.15 (SD 0.19) $\mathrm{mmol} / \mathrm{L}$ at 60 minutes $(p<0.01)^{34}$ (Appendix 5). However, there was no significant difference in the extent of reduction of serum potassium between the two treatment groups. There was a small but statistically significant increase in heart rate in the aminophylline group at 60 minutes, but otherwise no serious adverse effects occurred.

\section{Combination treatments}

Four studies evaluated combinations of treatment modalities in the management of hyperkalemia ${ }^{28,30-32}$ (Appendix 6, available at www.cmaj.ca/cgi/content/full/cmaj.100461/DC1). The first study reported a significantly greater decrease in serum potassium with combination intravenous insulin and nebulized albuterol relative to either treatment alone. ${ }^{28}$ The maximal effect, at 60 minutes, represented a decrease in serum potassium from baseline of $1.21(\mathrm{SD} 0.19) \mathrm{mmol} / \mathrm{L}$. Transient hyperglycemia was observed in this group.

Various two- and three-modality combinations of sodium bicarbonate, insulin and nebulized albuterol were tested against single agents in an RCT. ${ }^{31}$ All treatments (alone or in combination) decreased serum potassium within 30 to $60 \mathrm{~min}$ utes; however, the authors concluded that there was no significant difference in effect between treatment arms. In another study, infusion of bicarbonate in combination with intravenous insulin or nebulized albuterol conferred no additional benefit over either treatment alone in reducing serum potassium. ${ }^{30}$

In a study on the effect of laxatives and resins on serum potassium and fecal excretion of potassium in patients undergoing hemodialysis, there was a paradoxical increase in serum potassium after all treatments, but it was not significantly different from the effect of placebo. ${ }^{32}$ There was no sig- 
nificant difference in the total fecal excretion of potassium between either of these resin-containing treatments and phenolphthalein-docusate alone.

\section{Hemodialysis}

Five studies evaluated hemodialysis for the management of hyperkalemia ${ }^{23,24,29,35,36}$ (Appendix 7, available at www.cmaj.ca /cgi/content/full/cmaj.100461/DC1). Lower potassium dialy sate $^{35}$ and increased blood flow ${ }^{36}$ were reported to decrease potassium to a greater extent, whereas the effect of bicarbonate dialysate on potassium reduction was inconclusive. ${ }^{23,24}$

\section{When should potassium be rechecked?}

The studies reviewed here did not address the frequency and duration of monitoring of patients with hyperkalemia; therefore, recommendations regarding ongoing assessment are based on opinion. In the acute management of hyperkalemia, the frequency of monitoring depends on the potassium level, as well as underlying comorbidities. After initial interventions, potassium should be rechecked within one to two hours, to ensure effectiveness of the intervention, following which the frequency of monitoring could be reduced. Subsequent monitoring depends on the potassium level and the potential reversibility of the underlying cause.

\section{Gaps in knowledge}

Our review, which updates a prior systematic review,,$^{14}$ has highlighted the paucity of evidence to determine the most effective therapy for acute management of hyperkalemia. We were unable to identify randomized trial evidence to guide management of ECG changes associated with hyperkalemia, and evidence supporting gastrointestinal elimination of potassium was particularly limited. Furthermore, many studies included patients undergoing hemodialysis, which limits the generalizability of results.

\section{The case revisited and clinical implications}

Despite a lack of evidence from randomized trials, the current standard of care would dictate that the patient undergo immediate intravenous administration of calcium-based salts $(1 \mathrm{~g}$ calcium chloride or calcium gluconate) ${ }^{37}$ to address ECG changes consistent with severe hyperkalemia and thus to prevent deterioration to fatal arrhythmias.

Therapy to shift the potassium into the cells should also be instituted without delay. According to the results of the studies reviewed, intravenous insulin and $\beta_{2}$-adrenergic agonists have the quickest onset and, when administered together, are more effective than either treatment alone. $\beta_{2}$-Agonists are equally effective in all formulations; however, for ease of accessibility and administration, the nebulized form may be most appropriate. In this particular case, we recommend a dose of $10 \mathrm{mg}$ of nebulized salbutamol, which may be repeated if the serum potassium remains above $6.0 \mathrm{mmol} / \mathrm{L}$ after one to two hours. Because of the adverse effects of $\beta_{2}$-agonists, 10 units of shortacting intravenous insulin, combined with 12.5 to $25 \mathrm{~g}$ of dex- trose, might be preferable, if a single potassium-shifting therapy is thought to be adequate. The use of intravenous bicarbonate in this situation is supported by only weak and conflicting information; therefore, we cannot recommend its routine use in the management of hyperkalemia. The possible exception is treatment in the presence of concurrent metabolic acidemia, but this is based on opinion rather than evidence.

Rebound after potassium-shifting therapy occurs within two hours; if significant excretion of potassium during that period is unlikely - for example, by urine output or hemodialysis - consideration should be given to starting an infusion of glucose and insulin after the initial bolus, with close point-of-care monitoring of glucose; however, no evidence supports this method of administration. A resin, to bind potassium in the gut, administered with a laxative such as lactulose, may also be indicated at this point. An electrolyte panel should be repeated within one to two hours of instituting any of the above therapies, with subsequent laboratory monitoring as indicated by the clinical situation.

Once the hyperkalemia has resolved, the clinician should try to identify and modify the precipitants to reduce the risk of similar occurrences in the future. Further studies are required to guide the acute management of hyperkalemia.

\section{This article has been peer reviewed.}

Competing interests: Catherine Clase has received research grants from Baxter, Gambro and Astellas and served as a board member for Amgen. No competing interests declared by Meghan Elliott, Paul Ronksley, Sofia Ahmed and Brenda Hemmelgarn.

Contributors: Meghan Elliott and Brenda Hemmelgarn conceived the study. All of the authors participated in the systematic review of the literature. Meghan Elliott and Brenda Hemmelgarn abstracted the data, summarized the results and drafted the article. All of the authors critically revised the article for important intellectual content and approved the final version submitted for publication.

Acknowledgements: Paul Ronksley is supported by an International Chronic Disease Collaboration and University of Calgary Queen Elizabeth II Graduate Scholarship. Brenda Hemmelgarn and Sofia Ahmed are supported by New Investigator Awards from the Canadian Institutes of Health Research and by career salary awards from the Alberta Heritage Foundation for Medical Research.

\section{REFERENCES}

1. Moore ML, Bailey RR. Hyperkalaemia in patients in hospital. N Z Med J 1989; 102:557-8.

2. Stevens MS, Dunlay RW. Hyperkalemia in hospitalized patients. Int Urol Nephrol 2000;32:177-80

3. Paice B, Gray JM, McBride D, et al. Hyperkalaemia in patients in hospital. Br Med $J($ Clin Res Ed) 1983;286:1189-92.

4. Shemer J, Modan M, Ezra D, et al. Incidence of hyperkalemia in hospitalized patients. Isr J Med Sci 1983;19:659-61.

5. Acker CG, Johnson JP, Palevsky PM, et al. Hyperkalemia in hospitalized patients: causes, adequacy of treatment, and results of an attempt to improve physician compliance with published therapy guidelines. Arch Intern Med 1998;158:917-24.

6. Indermitte J, Burkolter S, Drewe J, et al. Risk factors associated with a high velocity of the development of hyperkalaemia in hospitalised patients. Drug Saf 2007; 30:71-80.

7. Juurlink DN, Mamdani MM, Lee DS, et al. Rates of hyperkalemia after publication of the Randomized Aldactone Evaluation Study. N Engl J Med 2004;351:543-51.

8. Surawicz B. Relationship between electrocardiogram and electrolytes. Am Heart J 1967;73:814-34.

9. Freeman K, Feldman JA, Mitchell P, et al. Effects of presentation and electrocardiogram on time to treatment of hyperkalemia. Acad Emerg Med 2008;15:239-49.

10. Fisch C. Relation of electrolyte disturbances to cardiac arrhythmias. Circulation 1973;47:408-19.

11. Alfonzo AV, Isles C, Geddes C, et al. Potassium disorders - clinical spectrum and emergency management. Resuscitation 2006;70:10-25. 
12. Weisberg LS. Management of severe hyperkalemia. Crit Care Med 2008;36:3246-51

13. Iqbal Z, Friedman EA. Preferred therapy of hyperkalemia in renal insufficiency: survey of nephrology training-program directors. N Engl J Med 1989;320:60-1.

14. Mahoney BA, Smith WA, Lo DS, et al. Emergency interventions for hyperkalaemia. Cochrane Database Syst Rev 2005;(2):CD003235.

15. Egger M, Smith GD, Altman DG, editors. Systematic reviews in health care: metaanalysis in context. 2nd ed. London (UK): BMJ Publishing Group; 2001.

16. Jadad AR, Moore RA, Carroll D, et al. Assessing the quality of reports of randomized clinical trials: Is blinding necessary? Control Clin Trials 1996;17:1-12.

17. Liberati A, Altman DG, Tetzlaff J, et al. The PRISMA statement for reporting systematic reviews and meta-analyses of studies that evaluate health care interventions: explanation and elaboration. Ann Intern Med 2009;151:W65-W69.

18. Kocoglu H, Goksu S, Pence S, et al. Treatment of hyperkalemia with high dose intravenous insulin during extracorporeal circulation. Cardiovasc Eng 2003;8:40-3.

19. Mushtaq MA, Masood M. Treatment of hyperkalemia with salbutamol and insulin Pak J Med Sci 2006;22:176-9.

20. Kim DM, Chung JH, Yoon SH, et al. Effect of fludrocortisone acetate on reducing serum potassium levels in patients with end-stage renal disease undergoing haemodialysis. Nephrol Dial Transplant 2007;22:3273-6.

21. Pancu D, LaFlamme M, Evans E, et al. Levalbuterol is as effective as racemic albuterol in lowering serum potassium. J Emerg Med 2003;25:13-6.

22. Balanzario JM, Nuevo JJL, Gaeta DEH, et al. Efecto del salbutamol intravenoso vs salbutamol en micronebulizador en la hipercaliemia por insuficiencia renal cronica. Med Int Mex 2003;19:202-5.

23. Capdevila M, Ruiz IM, Ferrer C, et al. The efficiency of potassium removal during bicarbonate hemodialysis. Hemodial Int 2005;9:296-302.

24. Heguilen RM, Sciurano C, Bellusci AD, et al. The faster potassium-lowering effect of high dialysate bicarbonate concentrations in chronic haemodialysis patients. Nephrol Dial Transplant 2005;20:591-7.

25. Kaisar MO, Wiggins KJ, Sturtevant JM, et al. A randomized controlled trial of fludrocortisone for the treatment of hyperkalemia in hemodialysis patients. Am J Kidney Dis 2006;47:809-14.

26. Li Q, Zhou MT, Wang Y, et al. Effect of insulin on hyperkalemia during anhepatic stage of liver transplantation. World J Gastroenterol 2004;10:2427-9.

27. Allon M, Dunlay R, Copkney C. Nebulized albuterol for acute hyperkalemia in patients on hemodialysis. Ann Intern Med 1989;110:426-9.

28. Allon M, Copkney C. Albuterol and insulin for treatment of hyperkalemia in hemodialysis patients. Kidney Int 1990;38:869-72.

29. Allon M, Shanklin N. Effect of albuterol treatment on subsequent dialytic potas sium removal. Am J Kidney Dis 1995;26:607-13.

30. Allon M, Shanklin N. Effect of bicarbonate administration on plasma potassium in dialysis patients: interactions with insulin and albuterol. Am J Kidney Dis 1996; 28:508-14.

31. Ngugi NN, McLigeyo SO, Kayima JK. Treatment of hyperkalaemia by altering the transcellular gradient in patients with renal failure: effect of various therapeutic approaches. East Afr Med J 1997;74:503-9.

32. Gruy-Kapral C, Emmett M, Santa Ana CA, et al. Effect of single dose resincathartic therapy on serum potassium concentration in patients with end-stage renal disease. J Am Soc Nephrol 1998;9:1924-30.

33. Mandelberg A, Krupnik Z, Houri S, et al. Salbutamol metered-dose inhaler with spacer for hyperkalemia: How fast? How safe? Chest 1999;115:617-22.

34. Mahajan SK, Mangla M, Kishore K. Comparison of aminophylline and insulindextrose infusions in acute therapy of hyperkalemia in end-stage renal disease patients. J Assoc Physicians India 2001;49:1082-5.

35. Zehnder C, Gutzwiller JP, Huber A, et al. Low-potassium and glucose-free dialysis maintains urea but enhances potassium removal. Nephrol Dial Transplant 2001; 16:78-84.

36. Gutzwiller JP, Schneditz D, Huber AR, et al. Increasing blood flow increases $\mathrm{kt} / \mathrm{V}$ (urea) and potassium removal but fails to improve phosphate removal. Clin Nephrol 2003;59:130-6.

37. ECC Committee, Subcommittees and Task Forces of the American Heart Association. 2005 American Heart Association guidelines for cardiopulmonary resuscitation and emergency cardiovascular care. Part 10.1: Life-threatening electrolyte abnormalities. Circulation 2005;112(24 Suppl I):IV121-5.

Correspondence to: Dr. Brenda R. Hemmelgarn, Division of Nephrology, Foothills Medical Centre, 1403 29th St. NW, Calgary AB T2N 2T9; brenda.hemmelgarn@albertahealthservices.ca

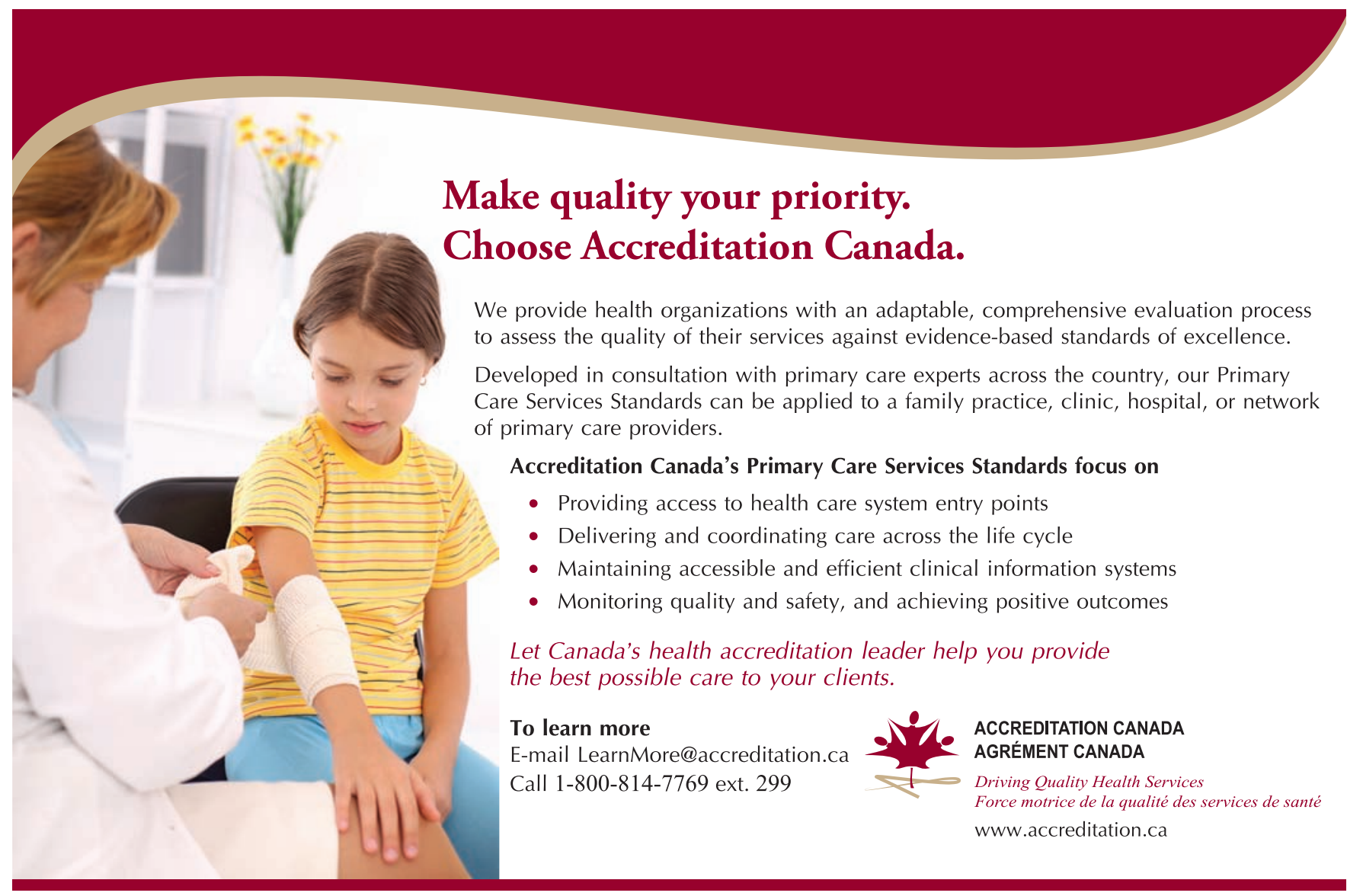

